\title{
Radon exposure: Can we make a difference?
}

\section{Ray Copes MD MSc, Jeff Scott MD}

$\mathrm{F}$ rom a public health perspective, radon is second only to smoking as a cause of lung cancer. It is estimated to cause about $10 \%$ of lung cancers, ${ }^{1,2}$ or more than 2000 cases each year in Canada. Radon is recognized as a group I carcinogen by the International Agency for Research on Cancer. ${ }^{3}$ In addition, there is a synergistic effect between cigarette smoking and radon gas in the development of lung cancer. At equivalent levels of radon exposure, people who smoke are at higher risk for lung cancer than nonsmokers (Box I).

Radon is a colourless, odourless inert radioactive gas. It occurs naturally in soil and rocks as uranium decays. Radon has a half-life of 3.82 days, and it decays into a series of short-lived radioisotopes (often referred to as radon daughters or radon decay products) that can be inhaled. The movement of radon gas into basements and ground-level living areas can result in a much higher level of radiation exposure indoors than would occur outdoors. Because of this, and because it is not feasible to reduce the radon level outdoors, radon-reduction initiatives have been targeted at reducing indoor exposure.

\section{New Canadian guideline for radon exposure}

Health Canada has recently updated its guideline for the acceptable level of radon in indoor air from $800 \mathrm{~Bq} / \mathrm{m}^{3}$ to $200 \mathrm{~Bq} / \mathrm{m}^{3}$ (Box 2). ${ }^{4}$ (A becquerel, or Bq, is the amount of material that will produce I nuclear disintegration per second). This brings the Canadian guideline closer to the guidelines adopted by other countries. Switzerland has a guideline of $400 \mathrm{~Bq} / \mathrm{m}^{3}$, and China, Australia and most of Europe have set a guideline of $200 \mathrm{~Bq} / \mathrm{m}^{3} .{ }^{4}$ The United States continues to have the most stringent guideline $\left(150 \mathrm{~Bq} / \mathrm{m}^{3}\right) .{ }^{4}$ Several European countries have been moving aggressively to develop and implement strategies to reduce radon exposure. In January 2002, the European Commission established an ongoing scientific-led industrial forum aimed at sharing the progress in radon programs made by over 20 countries and disseminating research findings to industry and the public.

Even with the new Canadian guideline, lifetime exposure at $200 \mathrm{~Bq} / \mathrm{m}^{3}$ is still associated with a much greater risk of developing cancer than is permitted by most other guidelines and standards intended to protect against environmental carcinogens. Such guidelines frequently try to reduce the attributable lifetime cancer risk from the carcinogen of concern to the range I per Io 000-I 000 ooo. Reduction of the residual risk for radon exposure to this level is not possible.

Although the new Canadian guideline is welcome and overdue, the question remains whether the change in the acceptable level of indoor exposure will reduce the risk for
Box 1: Risk of lung cancer for smokers and nonsmokers, by lifetime exposure level ${ }^{4}$

\section{Smokers}

- Indoor exposure at $800 \mathrm{~Bq} / \mathrm{m}^{3}: 30 / 100$

- Indoor exposure at $200 \mathrm{~Bq} / \mathrm{m}^{3}: 17 / 100$

- Outdoor exposure: $12 / 100$

\section{Nonsmokers}

- Indoor exposure at $800 \mathrm{~Bq} / \mathrm{m}^{3}: 5 / 100$

- Indoor exposure at $200 \mathrm{~Bq} / \mathrm{m}^{3}: 2 / 100$

- Outdoor exposure: $1 / 100$

Box 2: Summary of the new Canadian radon guideline ${ }^{4}$

- Remedial measures should be undertaken in a dwelling* if the annual average radon concentration exceeds $200 \mathrm{~Bq} / \mathrm{m}^{3}$ in the normal occupancy area. $\dagger$

- The higher the radon concentration, the sooner remedial measures should be undertaken.

- When remedial action is taken, the radon level should be reduced to a value that is as low as is practicable.

- The construction of new dwellings should involve techniques that will minimize radon entry and will facilitate post-construction radon removal if necessary.

*Dwellings include homes, schools, hospitals, long-term care residences and correctional facilities.

†Normal occupancy areas include the parts of a dwelling where a person spends more than 4 hours per day.

radon-related cancer. This question is not because of scientific uncertainty, nor is it because of a lack of effective preventive measures. Instead, this question remains because Canada does not have a record of aggressive action for publicizing or implementing national action on radon.

Turning the new guideline into action to reduce radon exposure presents some challenges (Box 3). Although Canadians spend more time in their homes than in any other indoor environment, radon exposure, unlike many other environmental hazards, provokes little "outrage." Radon gas is naturally occurring, is undetectable by smell or sight and, although carcinogenic, it does not result in catastrophic events. These factors likely contribute to a perceived risk that is less than the actual risk.

Ray Copes is with the British Columbia Centre for Disease Control, and the Department of Health Care and Epidemiology, University of British Columbia, Vancouver, BC. Jeff Scott is with the Government of Nova Scotia, Halifax, NS. 
Box 3: Elements of a successful radon-reduction program

Information

- Radon mapping

- Public awareness

Testing

- Make accurate radon monitors readily available to homeowners at low or no cost

Reduction of high levels

- Provide understandable instructions on what can be done by the "do-it-yourselfer"

- Require certification or other quality assurance testing for radon-reduction contractors

Measures such as sealing basements against radon intrusion, depressurizing soil and improving ventilation have been proven effective for reducing radon levels. Building remediation efforts have focused on homes, both because of their design and because they are where people spend the most time. Perhaps because remediation of a private home is felt to be the responsibility of the homeowner and not the government, there has been little pressure for action from the public and from nongovernment organizations that are often effective advocates for environmental measures. A recent publication by the David Suzuki Foundation is an exception to this. ${ }^{5}$

\section{How can we ensure that the new guideline results in action?}

Radon levels vary considerably in different parts of Canada. They can also vary from one house to the next on the same street owing to differences in soil conditions and home construction. Radon levels are highest in basements and on the ground floor, and higher stories are generally not affected. Although testing of individual buildings is necessary, some radon-prone areas are known. For example, the interior regions of British Columbia have higher levels of radon compared to coastal regions. Although testing has been performed in some provinces and in the United States, we lack the nation-wide information necessary to construct a useful radon map of Canada. Such a map would provide useful guidance on where we should focus further efforts for radon testing and reduction. Identification of radon-prone areas would allow homeowners, public health officials and governments to focus on the parts of the country where the problem is the greatest. This might improve the cost-effectiveness, ${ }^{5}$ but not the effectiveness of radon-reduction programs.

Although educational materials about radon have been developed for homeowners, ${ }^{6}$ we should direct additional efforts to make testing easier and less expensive. Setting up a hotline for homeowners to request a radon monitor to test the levels in their home and allowing them to return the monitor for analysis may increase compliance with testing recommendations. Approved monitors could be made available at government offices in areas that have been identified as being radon prone. Ideally, this would be a national program and would be effectively delivered at the local or regional level, possibly through public health units. In addition, a program to train or certify contractors in radon reduction and to ensure that radon testing is performed in an accurate manner may also be helpful. Adding a question about radon levels to real estate disclosure forms could provide an additional incentive to homeowners to preform radon testing.

Governments can lead by example. Although private homes need to be tested, many public buildings and licensed facilities such as day-care centres and community-living facilities are also candidates for radon testing. British Columbia already has a program for testing schools and for mitigating exposure when necessary. Action to date has shown that reduction, typically $75 \%-90 \%$, is achievable at a relatively moderate cost. If governments publicly commit to performing radon testing for buildings in their jurisdictions, their advice to the public to test their homes will have more credibility. Nova Scotia, for example, has already begun testing public buildings.

Recent efforts by occupational health and safety regulators to restrict smoking in the workplace have reduced this workplace health risk for a sizable group of Canadians. Like environmental tobacco smoke, radon is a "nontraditional" workplace hazard that merits attention. Even if we spend less time at work than at home, the risk for cancer from radon at $200 \mathrm{~Bq} / \mathrm{m}^{3}$ is well above the target risk level set for many workplace carcinogens. Efforts by occupational health and safety regulators to assess radon and, where necessary, to reduce radon exposure in the workplace may also stimulate public awareness that the radon is "real." Many public buildings are also workplaces, and workplace health and safety regulators should be encouraged to adopt the new $200 \mathrm{~Bq} / \mathrm{m}^{3}$ guideline as their workplace limit.

Development and application of building code requirements designed to prevent the intrusion of radon and other soil gases into newly constructed buildings may be a sound preventive measure. The effectiveness of these measures should be evaluated.

Finally, physicians, particularly primary care physicians who practise in radon-prone areas, can encourage patients to have their homes checked for radon. For nonsmokers, this may be the single most effective measure to prevent lung cancer. Physicians' organizations can play an active role in lobbying governments at all levels to take action to implement the new radon guideline. Although there have been advances in the treatment of lung cancer, the relative 5 -year survival is only $14 \%$ for men and $17 \%$ for women. ${ }^{7}$ This is still a cancer with very serious morbidity and mortality - prevention is indeed better than cure.

This article has been peer reviewed.

Competing interests: None declared.

Contributors: Both of the authors contributed substantially to the conception and design of the manuscript. Ray Copes wrote the first draft, and Jeff Scott contributed additional material. Both of the authors revised the manuscript for important intellectual content and approved the final version for publication. 


\section{REFERENCES}

I. Krewski D, Lubin JH, Zielinski JM, et al. A combined analysis of North American case-control studies of residential radon and lung cancer. J Toxicol Environ Health A 2006;69:533-97.

2. Darby S, Hill D, Auvinen A et al. Radon in homes and risk of lung cancer: collaborative analysis of individual data from I $3_{3}$ European case-control studies. $B M J$ 2005;330:223. Epub 2004 Dec 2I ahead of print.

3. International Agency for Research on Cancer. France: The Agency; 2007. Available: http://monographs.iarc.fr/ENG/Classification/crthallalph.php (accessed 2007 Oct 4).

4. Health Canada. Report of the Radon Working Group on a new radon guideline for Canada. Ottawa: Health Canada; 2006 Mar. Available: www.hc-sc.gc.ca/ahc-asc /public-consult/consultations/col/radon/rep-rapp_e.html (accessed 2007 Aug 30).
5. Boyd DR. Radon: the unfamiliar killer. Vancouver: The David Suzuki Foundation; 2007. Available: www.polisproject.org/publications/researcharea/lawpoliticalecology (accessed 2007 Sept 25).

6. Canadian Mortgage and Housing Corporation. Radon: a guide for Canadian homeowners. Ottawa: Canadian Mortgage and Housing Corporation and Health Canada; i997. Available: www.cmhc-schl.gc.ca/odpub/pdf/6r945.pdf (accessed 2007 Sept 25).

7. National Cancer Institute of Canada. Canadian Cancer Statistics 2002. Toronto: The Institute; 2002. p. 77.

Correspondence to: Dr. Ray Copes, BC Centre for Disease Control, 655 West I2th Ave., Vancouver BC V5Z4R4; fax 604 660-6628; ray.copes@bccdc.ca 